\title{
Development of a Neuropsychological Battery for the Leukoaraiosis and Disability in the Elderly Study (LADIS): Experience and Baseline Data
}

\author{
Sofia Madureira ${ }^{a}$ Ana Verdelho ${ }^{a}$ José Ferro ${ }^{a}$ Anna-Maria Basile ${ }^{b}$ Hugues Chabriat ${ }^{c}$ \\ Timo Erkinjuntti $^{d}$ Franz Fazekas ${ }^{e}$ Michael Hennerici ${ }^{f}$ John O'Brien ${ }^{g}$ Leonardo Pantoni ${ }^{b}$ \\ Emilia Salvadori $^{\mathrm{b}}$ Philip Scheltens ${ }^{\mathrm{h}}$ Marieke C. Visser $^{\mathrm{h}}$ Lars-Olof Wahlund $^{\mathrm{i}}$ \\ Gunhild Waldemar ${ }^{j}$ Anders Wallink ${ }^{k}$ Domenico Inzitari ${ }^{b}$ on behalf of the LADIS Study \\ aServiço de Neurologia, Centro de Estudos Egas Moniz, Hospital de Santa Maria, Lisboa, Portugal; \\ ${ }^{b}$ Department of Neurological and Psychiatric Sciences, University of Florence, Florence, Italy; \\ 'Department of Neurology, Hôpital Lariboisière, Paris, France; ${ }^{d}$ Memory Research Unit, Department of \\ Clinical Neurosciences, Helsinki University, Helsinki, Finland; e Department of Neurology and MRI Institute,

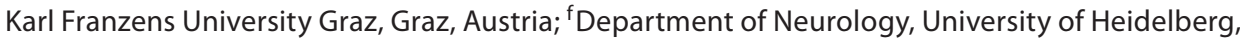 \\ Klinikum Mannheim, Mannheim, Germany; ${ }^{9}$ Institute for Ageing and Health, University of Newcastle, \\ Newcastle-upon-Tyne, UK; h Department of Neurology, VU Medical Center, Amsterdam, The Netherlands; \\ 'Karolinska Institute, Department of Clinical Neuroscience and Family Medicine, Huddinge University Hospital, \\ Huddinge, Sweden; ' ${ }^{M}$ emory Disorders Research Unit, Department of Neurology, Copenhagen University \\ Hospital, Copenhagen, Denmark; ${ }^{k}$ Institute of Clinical Neuroscience, Göteborg University, Göteborg, Sweden
}

\section{Key Words}

White matter changes $\cdot$ Aging $\cdot$ Cognitive performance $\cdot$

Neuropsychological tests

\begin{abstract}
The relationship between age-related white matter changes and cognitive performance in independent elderly people is still not clear. The Leukoaraiosis and Disability in the Elderly study (LADIS) involves 11 European centers. It aims to assess the role of the age-related white matter changes as an independent factor in the transition to disability, and in cognitive performance of an independent elderly population. A comprehensive neuropsychological battery was constructed in order to harmonize the cognitive assessment across countries. Patients were evaluated at baseline and during the 3year follow-up with the Mini-Mental State Examination, a modified version of the VADAS-Cog (Alzheimer's Dementia
\end{abstract}

Assessment Scale plus tests of Delayed recall, Symbol digit, Digit span, Maze, Digit cancellation and Verbal fluency), Trail making and Stroop test. Six hundred thirty-eight patients (mean age $74 \pm 5$ years; mean educational level $10 \pm 4$, F/M: 351/287) were included in this study. Neuropsychological data were analyzed test by test and also grouped in three compound measures (executive, memory and speed/motor control domains). Older subjects ( $>74$ years) performed significantly worse than younger subjects on the ADAS-Mod and on the tests of memory $\left(t_{631}=3.25 ; p=0.001\right)$, executive functions ( $\left.t_{581}=4.68 ; p=0.001\right)$ and speed $/$ motor control $\left(t_{587}=4.01 ; p=0.001\right)$. Participants with higher educational level ( $>8$ years of school) showed better performances on the compound measures for memory $\left(t_{631}=3.25 ; p=0.001\right)$, executive functions $\left(t_{581}=4.68 ; p=0.001\right)$ and speed $/$ motor control $\left(t_{587}=4.01 ; p=0.001\right)$. Using multiple regression analysis models to study the influence of demographic variables on cognitive performance, age and education remained im-

\section{KARGER}

Fax +4161306 1234 E-Mail karger@karger.ch www.karger.com
(C) 2006 S. Karger AG, Basel

0251-5350/06/0272-0101\$23.50/0

Accessible online at:

www.karger.com/ned
Sofia Madureira

Department of Neurosciences and Mental Health

Hospital Santa Maria

PT-1649-035 Lisbon (Portugal)

Tel./Fax +351 21795 7474, E-Mail pmadureira@fm.ul.pt 
portant variables influencing test performance. In the LADIS population baseline data, older age and lower educational levels negatively influence neuropsychological performance.

Copyright $\odot 2006$ S. Karger AG, Basel

\section{Introduction}

The relationship between age-related white matter changes (ARWMC) and cognitive impairment has been described in several studies in different population samples $[1,2]$.

In community-dwelling and independent elderly subjects, some studies reported an association between the presence of ARWMC and deficits in global mental functioning, speed of mental processing and memory [3-9]. However, others failed to find a relationship between the presence of ARWMC and cognitive performance [1012].

There are a number of factors that can explain the inconsistency of these results. They may be related to the design of the studies, the type of analysis performed on imaging and the neuropsychological evaluation. Further, regarding cognitive performance, the variability of results can be due to the use of different instruments and measures to assess cognition, the use of different criteria to define cognitively impaired performance, and the use of nonsensitive instruments, such as global measures of cognition, or tests sensitive to memory decline but not to executive functioning.

Despite the recent interest and effort to analyze the impact of ARWMC on cognition, there are still several issues that need to be explored. How is cognitive functioning influenced by ARWMC? Is there a threshold of ARWMC needed to affect cognition? Which cognitive domains are mainly affected by the presence of ARWMC and which domains are more sensitive to decline in parallel to the progression of ARWMC? Is there a neuropsychological profile related to the location of ARWMC?

The Leukoaraiosis and Disability in the Elderly study (LADIS) aims to assess the role of ARWMC as an independent predictor of disability in the elderly [13], contributing with answers to the above-mentioned issues. The LADIS study involves 11 centers of 10 European countries (appendix 1).

The assessment of cognitive functions is a difficult task, starting with the selection of the appropriate tests to evaluate specific domains. The difficulty increases in multinational studies since the performance in majority

of the tests is dependent on educational, language, cultural and demographic variables.

The aims of the present work were to describe the development of the LADIS neuropsychological battery, to present LADIS neuropsychological baseline data, and to discuss the methodological problems and limitations of the cognitive assessment within the LADIS study.

\section{Methods}

LADIS organization and methodology have already been reported elsewhere [13].

Construction of the Neuropsychological Battery

The construction of the LADIS neuropsychological battery took into consideration that: (1) selected tests had to be available and familiar in the majority of the centers; (2) the tests had to be sensitive to cognitive decline; (3) the battery had to be innovative, comprehensive, easy to administer, but not too long; (4) all centers had to use the same version of each test; (5) the original English version of tests had to be translated into each local language.

In order to construct the neuropsychological battery for the LADIS study, we performed a review of the studies investigating elderly samples with ARWMC using comprehensive cognitive assessments published until 2001, and selected the most frequently used instruments. In this review, we also retrieved the criteria for the definition of abnormal performance on the neuropsychological tests used in each study. A list of tests was made according to the frequency they appeared in the studies. All participating centers received a questionnaire in which, for each test of the list, several questions were asked: (a) if the test was available at their center; (b) if it was routinely used for cognitive assessment; (c) if it had local/national validation norms; (d) if the original or other versions were used.

Of the eight tests initially selected, the Mini-Mental State Examination (MMSE) [14] and the Stroop test $[15,16]$ were the only tests available and in use for assessment in all centers. However, the versions used were slightly different from center to center and normative values existed in only 62\% (MMSE) and 69\% (Stroop) of the countries. Verbal fluency tests were also available in all centers, with normative values for $92 \%$ of the countries. Nevertheless, the variability of versions was wide: some centers used semantic fluency (animals, colors, fruits, cities, or supermarket goods), others used only controlled oral word association tests (using different letters such as FAS, PFL or LPS). The Wisconsin Card Sorting Test [17] was available in almost all the centers, but with different versions (original and modified). Further, in half of the centers it was not used on a regular basis.

The following tests were initially selected for inclusion in the LADIS neuropsychological battery: the MMSE to assess global mental status, the Stroop and Trail making tests [18] to assess executive functions. In the absence of any frequently used battery, we added the VADAS-Cog [19] which is a recently developed instrument used to assess the cognitive performance of patients with vascular dementia. It is composed by the well-known Alzheimer's Disease Assessment Scale (ADAS-Cog) [20], which assesses memory, orientation, language, ideational and construc- 
Table 1. LADIS neuropsychological battery

\begin{tabular}{|c|c|c|c|c|c|c|c|c|c|c|}
\hline & \multirow[t]{2}{*}{ MMSE } & \multirow{2}{*}{$\begin{array}{l}\text { ADAS- } \\
\text { Mod }\end{array}$} & \multicolumn{5}{|l|}{ VADAS } & \multicolumn{2}{|c|}{ Trail making } & \multirow[t]{2}{*}{ Stroop } \\
\hline & & & $\begin{array}{l}\text { Symbol } \\
\text { digit }\end{array}$ & $\begin{array}{l}\text { Digit } \\
\text { span }\end{array}$ & Maze & $\begin{array}{l}\text { Digit } \\
\text { cancellation }\end{array}$ & $\begin{array}{l}\text { Verbal } \\
\text { fluency }\end{array}$ & A & B & \\
\hline Global mental functioning & + & + & & & & & & & & \\
\hline Orientation & & + & & & & & & & & \\
\hline Memory & & + & & + & & & & & & \\
\hline Attention & & & + & + & & + & & + & & \\
\hline Language & & + & & & & & & & & \\
\hline Constructional abilities & & + & & & & & & & & \\
\hline Executive functions & & & + & & & & + & & + & + \\
\hline Praxis & & + & & & & & & & & \\
\hline Speed and motor control & & & & & + & + & & + & & \\
\hline
\end{tabular}

MMSE = Mini-Mental State Examination; ADAS-Mod = Alzheimer's Disease Assessment Scale, Modified; VADAS = ADAS-Mod plus timed tests.

tional praxis in addition to other specific tests that evaluate memory with interference, attention and executive functions (Delayed recall, Symbol digit, Digit span, Maze, Digit cancellation, Verbal fluency). The psychometric properties of these tests have been previously described with elderly populations [21, 22]. Table 1 tabulates the neuropsychological tests composing the initial LADIS battery and the cognitive domains they assess.

In order to reduce the time needed to administer the VADASCog, only one trial was used on subtest 1 (Word recall) and subtest 8 (Word recognition), instead of the original three. On the VADAS-Cog, the translation of the words on subtests 1 and 8 was made according to the frequency of the words in each language [23]. On subtest 5 (Naming objects), we used drawings instead of real objects, as it was the best way to reduce the heterogeneity of administration. The subtest 'Delayed recall' of the words of subtest 1 was also included in the ADAS-Cog. This subtest is scored as the other items of the ADAS-Cog (higher score representing worse performance). Because of these modifications, we will use the designation ADAS-Mod instead of ADAS-Cog. Finally, part $\mathrm{B}$ of Trail making (original version) was locally adapted to the alphabet of each country.

The original English version of all tests was collected by the center responsible for the neuropsychological assessment work package and mailed to each center to be locally translated. A handbook with the instructions of all the tests was also distributed to the centers in order to guarantee that each instrument would be used in the same way.

For the 2nd year of follow-up, two additional tests were included: the 9-Word California Verbal Learning Test (CVLT) [24] and the Constructional praxis delayed recall, based on the CERAD battery [25], in order to improve the assessment of memory decline. Both these tests and the instrument used to assess participants who were unable to come to the visits - the Telephone Interview for Cognitive Status [26] - will be described and analyzed elsewhere, along with the results of the last follow-up.

\section{Analysis of Neuropsychological Data}

Neuropsychological data were analyzed as follows: (1) analysis of the test score distribution; (2) analysis of the differences on the neuropsychological performance related to the demographic variables and center; (3) analysis of the influence of demographic variables on cognitive performance; (4) analysis of the influence of other potential confounding variables such as visual deficit, previous stroke, or center of inclusion on the neuropsychological performance.

MMSE was used only as a global measure of cognitive functioning and analyzed either as a continuous variable or categorized using the cut-off of $\leq 23$ (for dementia), or $<25$ (for cognitive deficit) [27]. The Stroop test was considered a measure of executive function, and the analyzed measure was time used to perform Stroop 3 minus the time to perform Stroop 2. The Trail making test was considered a measure of executive functions using the score 'time needed to perform part $\mathrm{B}$ minus the time to perform part A'. Trail making/A score was also used as a measure of speed and motor control. Higher scores on both the Stroop and Trail making tests represented worse performance. VADAS-Cog was analyzed in two ways: (a) as a global measure, consisting of the scores of ADAS-Mod items Word recall, Commands, Constructional praxis, Delayed recall, Naming, Ideational praxis, Orientation, Word recognition, Remembering instructions, Spoken language ability, Word finding difficulty, Comprehension, and Concentration/distractibility. Higher scores represented worse performance; (b) the 5 additional subtests Digit span backwards, Maze task, Digit cancellation, Symbol digit and Verbal fluency were evaluated independently. In all the tests except for Maze (where the score is the time to complete the task), higher scores represent better performance.

Depending on the aim of the study performed on the LADIS sample, cognitive variables will be analyzed as continuous or categorical using specific cut-offs (e.g. MMSE) or the quartiles of the distribution of the LADIS sample (table 2). For the present paper, all the test scores were analyzed as continuous variables. 
Table 2. Quartiles of the distribution of the neuropsychological tests scores

\begin{tabular}{|c|c|c|c|c|c|c|c|c|c|c|c|c|c|c|c|}
\hline & & MMSE & $\begin{array}{l}\text { Stroop } \\
1\end{array}$ & $\begin{array}{l}\text { Stroop } \\
2\end{array}$ & $\begin{array}{l}\text { Stroop } \\
3\end{array}$ & $\begin{array}{l}\text { Stroop } \\
3-2\end{array}$ & $\begin{array}{l}\text { Trail } \\
\text { A }\end{array}$ & $\begin{array}{l}\text { Trail } \\
\text { B }\end{array}$ & $\begin{array}{l}\text { Trail } \\
\text { B - A }\end{array}$ & $\begin{array}{l}\text { ADAS- } \\
\text { TOTAL }\end{array}$ & $\begin{array}{l}\text { Symbol } \\
\text { digit }\end{array}$ & $\begin{array}{l}\text { Digit } \\
\text { span }\end{array}$ & Maze & $\begin{array}{l}\text { Digit } \\
\text { cancel }\end{array}$ & $\begin{array}{l}\text { Verbal } \\
\text { fluency }\end{array}$ \\
\hline Valid & & 638 & 628 & 626 & 619 & 618 & 633 & 605 & 605 & 633 & 627 & 635 & 632 & 626 & 631 \\
\hline Missing & & 2 & 12 & 14 & 21 & 22 & 7 & 35 & 35 & 7 & 13 & 5 & 8 & 14 & 9 \\
\hline Mean & & 27.3 & 12.0 & 17.0 & 50.9 & 34.1 & 63.5 & 177.3 & 116.8 & 16.6 & 26.8 & 5.4 & 7.4 & 19.5 & 18.9 \\
\hline Median & & 28.0 & 11.0 & 15.0 & 43.0 & 27.0 & 52.0 & 143.0 & 91.0 & 16.0 & 27.0 & 5.0 & 6.0 & 20.0 & 19.0 \\
\hline \multirow[t]{3}{*}{ Percentiles } & 25 & 26.0 & 9.0 & 13.0 & 32.0 & 18.0 & 41.0 & 106.0 & 59.0 & 12.0 & 19.0 & 4.0 & 4.0 & 14.0 & 14.0 \\
\hline & 50 & 28.0 & 11.0 & 15.0 & 43.0 & 27.0 & 52.0 & 143.0 & 91.0 & 16.0 & 27.0 & 5.0 & 6.0 & 20.0 & 19.0 \\
\hline & 75 & 29.0 & 14.0 & 19.0 & 60.0 & 42.0 & 72.5 & 233.5 & 154.0 & 20.0 & 35.0 & 6.0 & 8.7 & 24.0 & 23.0 \\
\hline Skewness & & -1.36 & 2.44 & 3.49 & 3.25 & 3.66 & 2.78 & 2.19 & 2.93 & 1.10 & 0.32 & 0.31 & 3.90 & 0.14 & 0.22 \\
\hline
\end{tabular}

The distribution of the test scores was analyzed for each variable. Non-normal distributions with marked skewness $(>2)$ were transformed into normal or less skewed distributions using a logarithmic transformation of the scores. Data analysis was conducted using both the raw and the transformed scores. As the results of raw and transformed scores were similar, the results based on raw scores were presented.

To compare performances across tests and by cognitive domain, we used Z-standard scores, using the distribution of the LADIS sample. To analyze performances by domain, compound measures were calculated using standard scores. Three main domains were analyzed: (1) memory $=\mathrm{z}$-scores of (Immediate word recall + Delayed recall + Word recognition + Digit span $) / 4$; (2) executive functions $=\mathrm{z}$-scores of $[($ Stroop $3-2)+($ Trail making/B - Trail making/A) + Symbol digit + Verbal fluency]/4; (3) speed and motor control = z-scores of (Trail making/A + Mazes + Digit cancellation)/3. Z-scores of the tests that had higher scores representing worse performance were inverted $(-Z)$ in order to calculate the compound measure score. A preliminary exploratory factor analysis was performed to evaluate the validity of the neuropsychological battery and the aforementioned compound measures using Principal Component Analysis as extraction method and Varimax Rotation. The obtained solution was compared with the theoretically derived dimensions.

The degree of ARWMC severity on MRI was rated into mild, moderate and severe using the visual scale of Fazekas et al. [28], taking only deep and subcortical white matter lesions into account.

The demographic variables considered for the present analysis were age, education, gender, living conditions (alone or with others), and employment status (retired, working). Age and education were analyzed as continuous variables, except when comparing demographic variables and neuropsychological performance where they were dichotomized using the median of the LADIS sample (74 years and 9 years, respectively).

There were several reasons for referral to the LADIS study, including minor cognitive or neurological complaints, stroke or other neurological disturbances [13]. Therefore, sources of referral were analyzed as variables that could influence the performance on neuropsychological testing. Other possible confounders for the analysis of cognitive performance, such as visual or hearing deficits, were also considered in data analysis.

\section{Statistical Analysis}

Descriptive statistics was performed to analyze the quality and distribution of the neuropsychological data. The distribution of demographic characteristics and test scores among centers was performed using box and whiskers plots. Differences among centers were calculated using one-way ANOVAs with Bonferroni or Tamhane's (equal variance not assumed) post-hoc analyses for multiple comparisons.

The neuropsychological performance in each test and domain was compared across demographic characteristics (age, sex, education, living conditions, employment status) using t tests. Performance across cognitive tests was also compared according to the sources of referral using one-way ANOVA with Bonferoni post-hoc analysis. In order to study the influence of demographic variables on cognitive performance, linear regression models (including all the significant variables in the previous comparisons, $\mathrm{p}<0.05)$ were performed for each neuropsychological test and domain. Possible confounding variables that could influence the results of neuropsychological performance, such as presence of visual or hearing deficits, previous stroke or center of origin, were also included in an additional linear regression model.

\section{Results}

\section{Baseline Neuropsychological Data}

Six hundred and thirty-nine patients were enrolled in the LADIS study. Baseline demographic and WMC characteristics, as well as the reasons for referral of the patients are shown in table 3 . Neuropsychological examination was performed on 638 (99.8\%) patients.

\section{Quality of Data and Distribution of the Test Scores}

The highest number of missing values (33 patients, 5\%) was observed on Trail making/part B (mental flexibility) and Stroop test/part 3 (3\%). Five-hundred and seventy-eight patients (91\%) had no missing values on the neuropsychological evaluation. Skewed distributions with a ceiling effect were observed in the subtests Command, Naming, Ideational praxis, Orientation, Mazes, 
Table 3. Baseline demographic WMC characteristics and reasons for referral of the patients

\begin{tabular}{lc}
\hline Study population $(\mathrm{n}=638)$ & \\
\hline Demographic factors & \\
Age, mean \pm SD, years & $74.1 \pm 5$ \\
Female/male & $9.6 \pm 3.8$ \\
Education, mean \pm SD, years & $205(32 \%) / 434(68 \%)$ \\
Living alone/with other & $24(4 \%) / 610(96 \%)$ \\
Working/retired & $401(63 \%) / 237(37 \%)$ \\
Married/not married & \\
\hline WMC characteristics & $284(44.5 \%)$ \\
Mild & $196(30.7 \%)$ \\
Moderate & $158(24.8 \%)$ \\
Severe & \\
\hline Reasons for referral & $168(26.3 \%)$ \\
Minor cognitive complaints & $122(19.1 \%)$ \\
Minor stroke & $28(4.4 \%)$ \\
Motor complaints & $13(2 \%)$ \\
Psychic complaints & $107(16.7 \%)$ \\
Incidental CT/MRI findings & \\
Other neurological disturbances & $129(20.2 \%)$ \\
Controls in other studies or volunteers & $72(11.3 \%)$ \\
\hline
\end{tabular}

${ }^{a}$ Subjects undergoing a neuroimaging study for nonspecific reasons such as tension headache, dizziness, minor trauma, hearing complaints.

Remembering instructions, Spoken language, Word finding difficulties, Comprehension and Concentration (fig. 1), which were transformed using the logarithmic of the scores. There were no differences in the results either using transformed or raw scores (data available on request).

\section{Preliminary Exploratory Factor Analysis}

Factor analysis of principal components with varimax rotation extracted three factors. The eigenvalues for the 3 factors were $5.90,1.44$ and 1.41, explaining $48.6 \%$ of the total variance. For factor 1 , the most salient tests were Trail A, Trail B, Trail B - A, Symbol digit, Digit cancellation, Maze task and Verbal fluency. We denominated this factor as executive functions. Factor 2 was designated as Selective Attention because only Stroop 3 and Stroop 3 - 2 were loaded saliently. Factor 3 was designated as memory because the loadings of the tests of memory, i.e. Immediate word recall, Delayed word recall, Word recognition and Orientation, were the most salient. For the compound measure scores, we excluded the simplest timed tests, i.e. Trail A, Maze task and Digit cancellation from the executive functions, and added the Stroop test, for theoretical and interpretability reasons. The timed tests were grouped into a speed/motor control measure.

\section{Distribution of the Test Scores by Center}

Significant differences among centers were observed for all tests (one-way ANOVAs). Post-hoc analysis (Bonferroni's analysis was employed for all tests, except for Symbol digit and Verbal fluency which were analyzed with Tamanhe's test) showed that differences were randomly distributed, and no consistent pattern was found (there was no center always better or worse than the others). Figure 1 shows the distribution of the test scores by center.

The distribution of age and education by center was analyzed, as they are important variables for neuropsychological performance. No significant differences were found among centers with respect to age $\left(\mathrm{F}_{10,628}=1.27\right.$; $\mathrm{p}=0.24)$. Education had a normal distribution with significant differences among centers $\left(\mathrm{F}_{10,627}=11.76\right.$; $\mathrm{p}<$ 0.001). Using Bonferroni post-hoc test, we found that Lisbon and Florence centers differed systematically from the other centers as they had the lowest mean educational levels ( $\mathrm{p}<0.01$ for both).

Mean Differences regarding Demographic Variables

Table 4 shows the differences in neuropsychological performance according to the demographic variables.

Age. Older subjects ( $>74$ years) performed significantly worse than younger subjects on the ADAS-Mod Total based on the differences found on ADAS-Mod subtests Constructional praxis $\left(\mathrm{t}_{513}=-3.09 ; \mathrm{p}<0.01\right)$ and Delayed recall $\left(\mathrm{t}_{607}=-3.12 ; \mathrm{p}<0.01\right)$. Older subjects also showed worse performances on Stroop part $3\left(\mathrm{t}_{617}=-2.63\right.$; $\mathrm{p}<$ $0.01)$, Trail making A $\left(\mathrm{t}_{537}=-3,16 ; \mathrm{p}<0.01\right)$ and $\mathrm{B}\left(\mathrm{t}_{456}=\right.$ $-3.40 ; \mathrm{p}<0.01)$, Symbol digit $\left(\mathrm{t}_{625}=3,72 ; \mathrm{p}<0.01\right)$, Digit cancellation $\left(\mathrm{t}_{631}=4.94 ; \mathrm{p}<0.001\right)$ and verbal fluency $\left(\mathrm{t}_{629}=-2.83 ; \mathrm{p}<0.01\right)$. Comparing the performance by cognitive domain, older subjects performed worse than younger subjects on executive functions $\left(\mathrm{t}_{581}=4.68\right.$; $\mathrm{p}<$ 0. 01$)$, memory $\left(\mathrm{t}_{631}=3.25 ; \mathrm{p}<0.01\right)$ and speed $/$ motor control $\left(\mathrm{t}_{587}=4.01 ; \mathrm{p}<0.01\right)$.

Gender. Women performed significantly worse on the ADAS-Mod subtest Constructional praxis $\left(\mathrm{t}_{635}=3.18\right.$; $\mathrm{p}<0.01)$ and Maze $\left(\mathrm{t}_{630}=2.54 ; \mathrm{p}<0.01\right)$. There were no gender differences considering the three cognitive domains: executive functions ( $\left.\mathrm{t}_{581}=-0.99 ; \mathrm{p}=0.31\right)$, memory $\left(\mathrm{t}_{628}=-0.18 ; \mathrm{p}=0.85\right)$ and speed/motor control $\left(\mathrm{t}_{621}=-1.46 ; \mathrm{p}=0.14\right)$. 


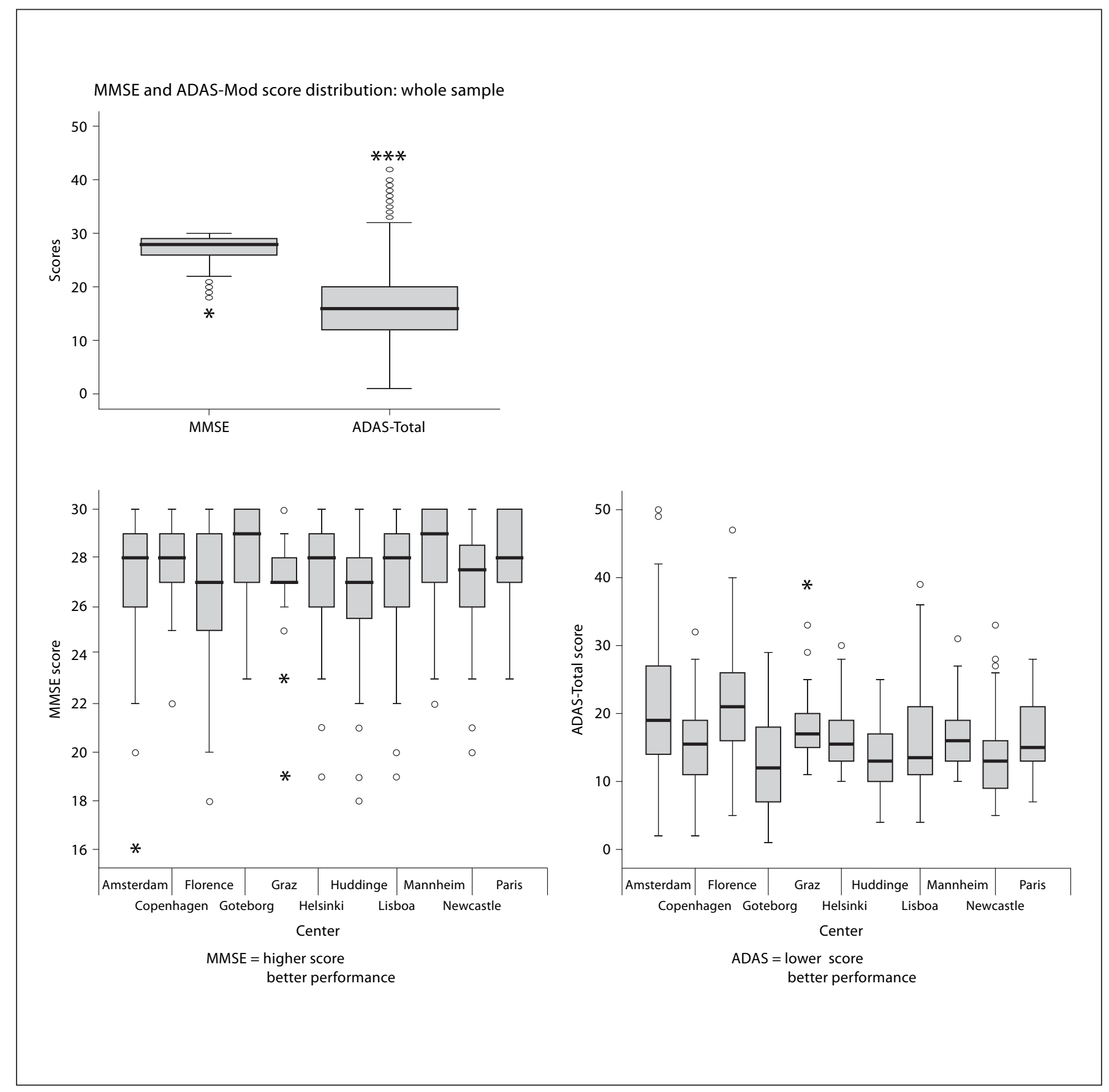

Fig. 1. Distribution of the test scores of the whole sample and by center. Box and whiskers represent the upper quartile (top of the box) and the lower quartile (bottom); bar represents the median; the largest value is on the superior whisker; the smallest value is on the inferior whisker. Open circles and asterisks signify outliers and extreme scores, respectively.

(For figure 1 see next pages.) 

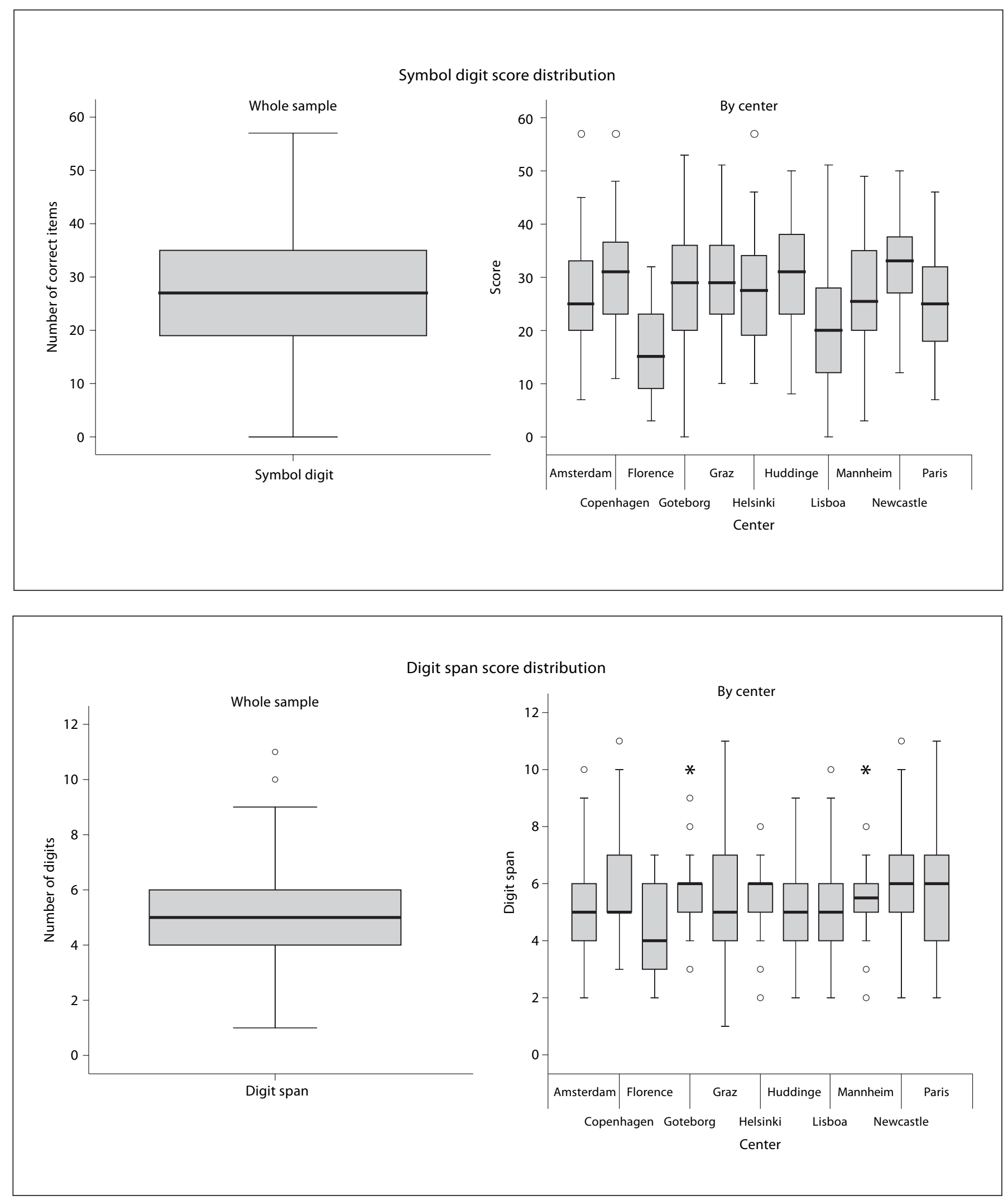

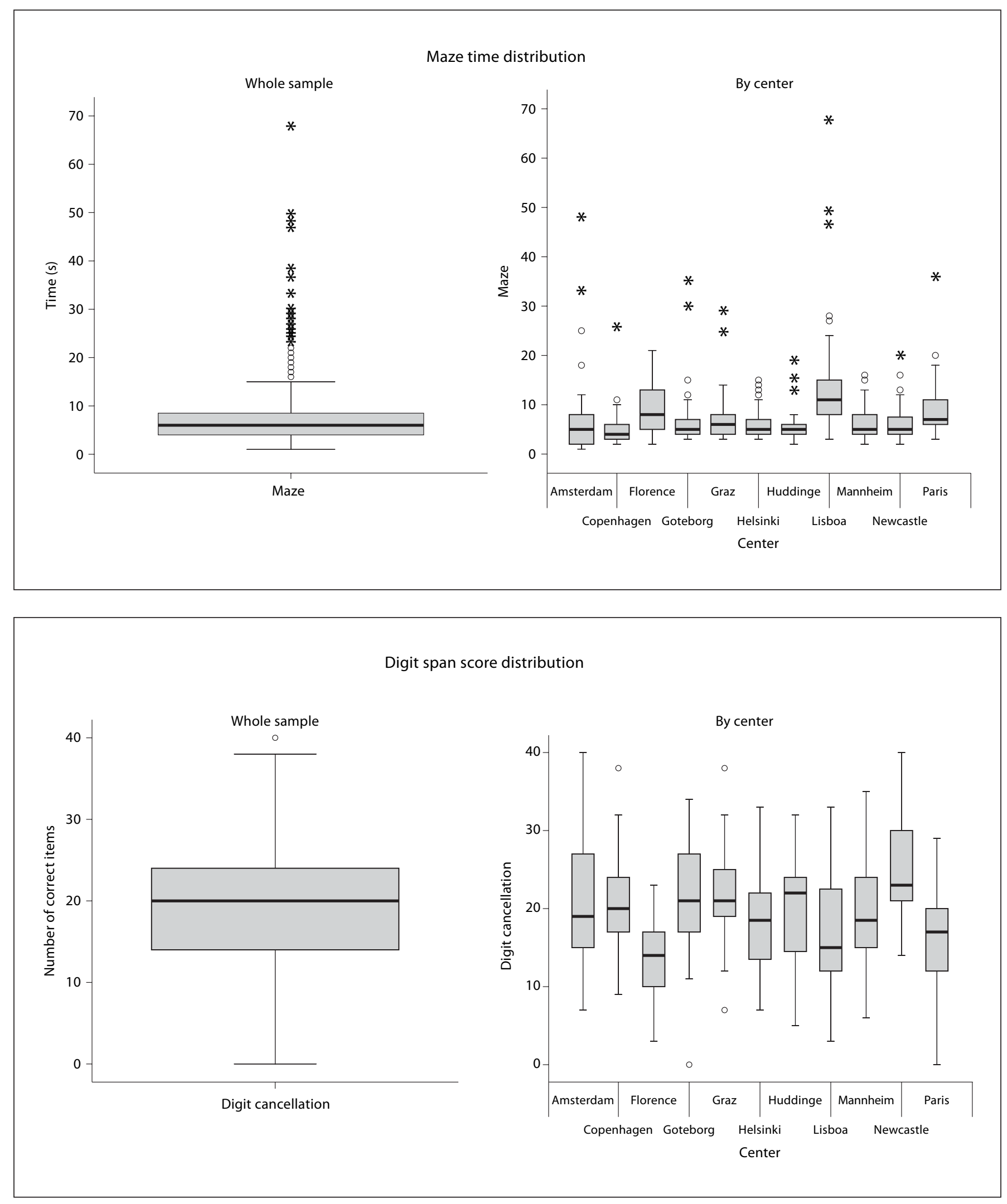

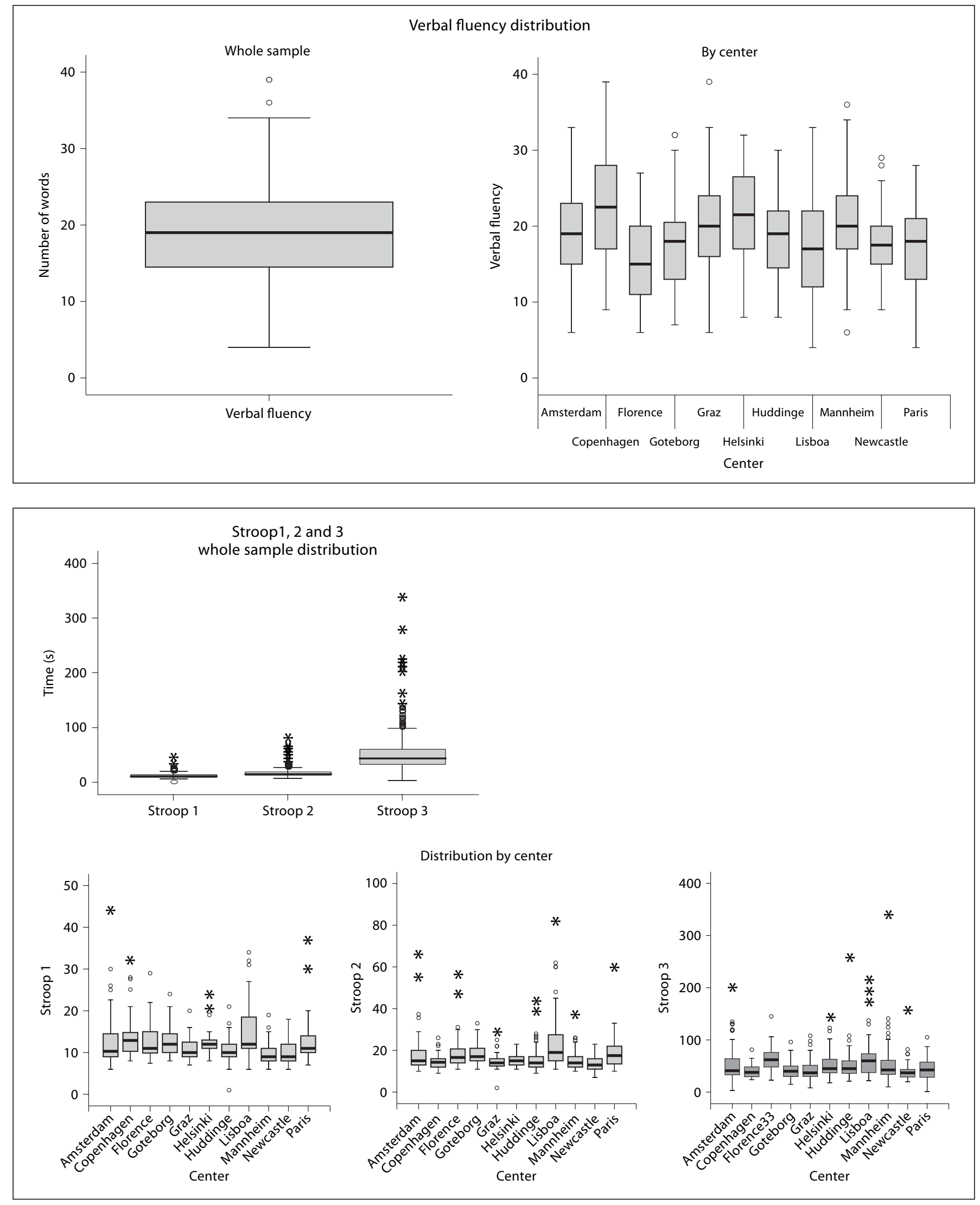


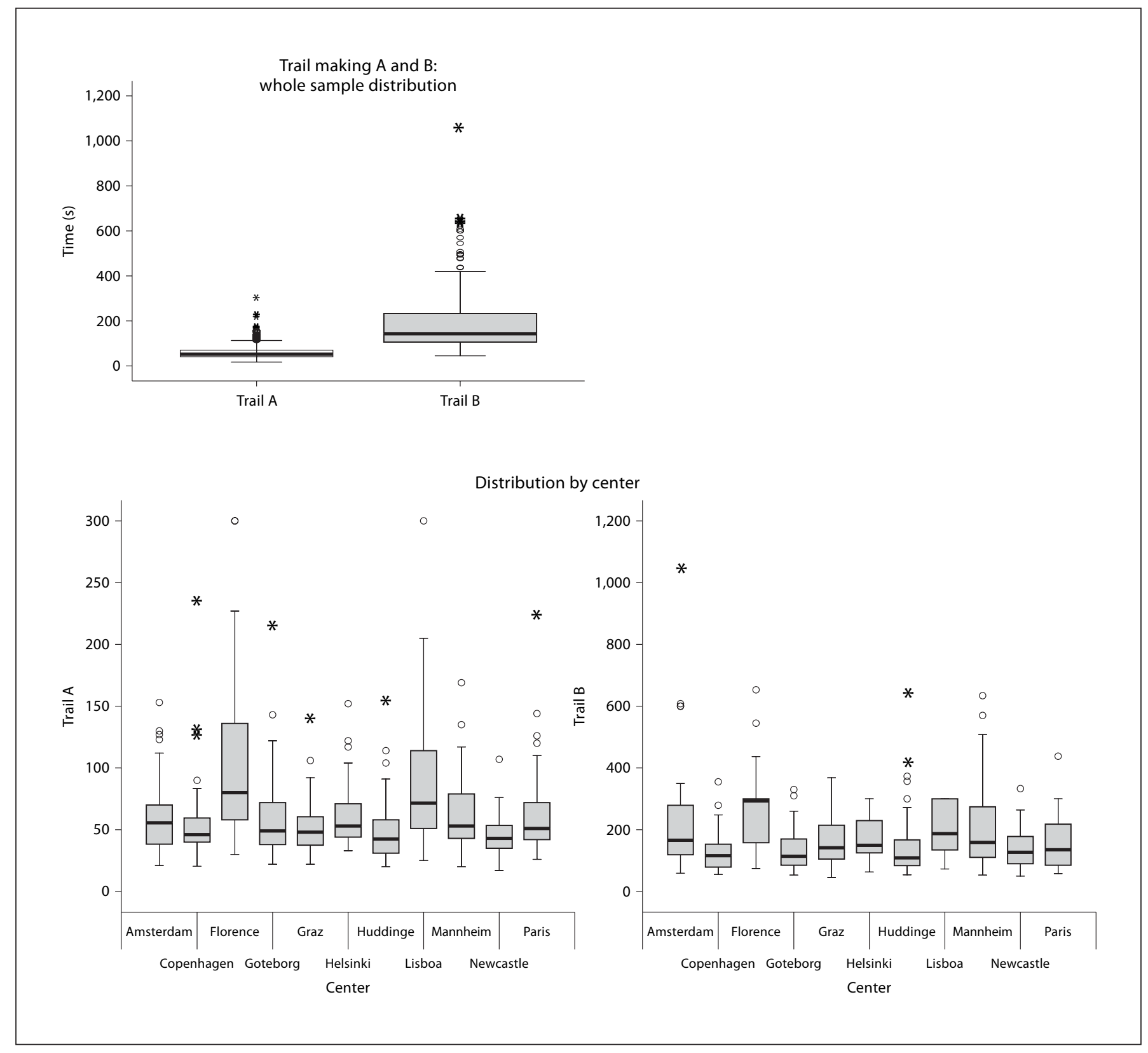

Education. Significant differences between subjects with higher ( $>8$ years of school) and lower educational level ( $<9$ years) were observed on all tests, except on ADAS-Mod Orientation ( $\mathrm{t}_{555}=1.93 ; \mathrm{p}=0.05$, not shown in table 4), Immediate word recall $\left(\mathrm{t}_{635}=1.59 ; \mathrm{p}=0.11\right)$, Word recognition $\left(\mathrm{t}_{633}=1.93 ; \mathrm{p}=0.05\right)$, and Commands $\left(\mathrm{t}_{577}=1.94 ; \mathrm{p}=0.05\right)$. Considering the compound measures of cognitive domains, subjects with lower educational level had worse performances on executive functions $\left(\mathrm{t}_{581}=-10.74 ; \mathrm{p}<0.01\right)$, memory $\left(\mathrm{t}_{631}=-4.99\right.$; $\mathrm{p}<0.01)$, and speed/motor control $\left(\mathrm{t}_{381}=-8.36 ; \mathrm{p}<\right.$ $0.01)$.

Living Conditions. Participants who lived alone tended to perform better on Trail making A $\left(\mathrm{t}_{568}=2.19 ; \mathrm{p}<0.05\right)$. However, there were no differences on the other tests, or on the cognitive domains executive functions $\left(t_{581}=0.52\right.$; $\mathrm{p}=0.60)$, memory $\left(\mathrm{t}_{631}=0.46 ; \mathrm{p}=0.64\right)$ and speed $/$ motor control $\left(t_{530}=-1.20 ; p=0.22\right)$. As it was not a significant variable, it was not included in the regression models. 
Employment Status. Participants who were still working performed worse on the ADAS-Mod Commands $\left(t_{29}=-3.28 ; \mathrm{p}<0.01\right)$. No differences were found in other tests, or on cognitive domains executive functions $\left(\mathrm{t}_{576}=\right.$ $1.48 ; \mathrm{p}=0.14)$, memory $\left(\mathrm{t}_{626}=1.05 ; \mathrm{p}=0.29\right)$ and speed $/$ motor control $\left(\mathrm{t}_{616}=1.02 ; \mathrm{p}=0.31\right)$. As participants still working represented only $4 \%$ of the LADIS population, this variable was also not included in the regression models.

Neuropsychological performance was also compared by sources of referral. Using a one-way ANOVA, we found significant differences in all the cognitive tests, except for the MMSE $\left(\mathrm{F}_{6,631}=0.72 ; \mathrm{p}=0.63\right)$, ADASMod subtests Word recall $\left(\mathrm{F}_{6,630}=1.93 ; \mathrm{p}=0.07\right)$, Commands $\left(\mathrm{F}_{6,630}=1.33 ; \mathrm{p}=0.24\right)$ and Constructional praxis $\left(\mathrm{F}_{6,630}=1.67 ; \mathrm{p}=0.12\right)$. Post-hoc analysis showed that healthy volunteers performed better in all the cognitive tests compared with patients with previous stroke or other complaints.

\section{Multiple Regression Analysis}

Multiple linear regression models were used to analyze the influence of the demographic variables on the neuropsychological performance. Table 5 shows the analyses performed with model 1 , that included the variables age, education and gender; model 2 , with added possible confounders, such as previous stroke, and any complaint or visual deficit, and model 3 , in which center origin was added as a covariable. Age remained an important variable influencing the performance on ADAS-Mod Total $\left(\mathrm{R}^{2}=0.10 ; \mathrm{F}_{2,630}=35.41 ; \beta=0.17 ; \mathrm{p}<0.001\right)$ and cognitive domains executive functions $\left(\mathrm{R}^{2}=0.22 ; \mathrm{F}_{2}, 580=\right.$ 79.99; $\beta=-0.22, p<0.001)$, and speed/motor control $\left(\mathrm{R}^{2}=0.16 ; \mathrm{F}_{2,619}=59.68 ; \beta=-0.17, \mathrm{p}<0.001\right)$.

There was no other significant influence of gender on neuropsychological performance except on ADAS-Mod Constructional praxis $\left(\mathrm{R}^{2 \text { change }}=0.004 ; \mathrm{F}_{6,629}=10.62\right.$; $\beta=-0.10, p<0.01)$.

Education remained an important variable influencing the performance on all the tests and domains of executive functions, memory, and speed/motor control (table 5).

Variables that might work as confounders of cognitive performance, such as 'referral for any complaint' (vs. healthy volunteers), and previous stroke and visual problems, were included on the second linear regression model. To have any complaint remained an important variable influencing the performance on Trail making A $\left(\mathrm{R}^{2}\right.$ change $\left.=0.02 ; F_{6,625}=19.48 ; \beta=0.12, p<0.01\right)$, Trail making $B-A\left(R^{2}\right.$ change $=0.10 ; F_{16,587}=11.81 ; \beta=0.10, p<$ $0.01)$, Symbol digit $\left(\mathrm{R}^{2}\right.$ change $=0.03 ; \mathrm{F}_{6,619}=44.90$; $\beta=-0.13, p<0.001)$, Digit cancellation $\left(R^{2 \text { change }}=0.06\right.$; $\left.\mathrm{F}_{6,618}=31.90 ; \beta=-0.21, \mathrm{p}<0.001\right)$, Digit span $\left(\mathrm{R}^{2}\right.$ change $\left.=0.01 ; \mathrm{F}_{6,627}=18.62 ; \beta=-0.10, \mathrm{p}<0.01\right)$ and compound measures speed $/$ motor control $\left(\mathrm{R}^{2}\right.$ change $=0.03 ; \mathrm{F}_{6,615}=$ 24.03; $\beta=-0.12, p<0.001)$ and executive functions $\left(R^{2}\right.$ change $\left.=0.02 ; F_{6,576}=30.32 ; \beta=-0.10, p<0.01\right)$. When visual impairment was included on the linear regression models, its influence was observed on the performance in Trail making $\mathrm{B}-\mathrm{A}\left(\mathrm{R}^{2}\right.$ change $=0.10 ; \mathrm{F}_{16,587}=11.81$; $\beta=0.10, p<0.01)$, Maze task $\left(\mathrm{R}^{2 \text { change }}=0.03 ; \mathrm{F}_{6,624}=\right.$ $14.57 ; \beta=0.15, \mathrm{p}<0.001)$ and Delayed recall $\left(\mathrm{R}^{2}\right.$ change $=$ $\left.0.03 ; \mathrm{F}_{6,628}=10.34 ; \beta=-0.12, \mathrm{p}<0.01\right)$.

On the third step of the models, center of origin was included as covariable. We found that centers influenced the performance of all the tests, but again the findings were randomly distributed and there was no center influencing systematically all the dependent variables in the same way (table 5).

In all the models, age and education remained important factors for neuropsychological performance.

\section{Discussion}

\section{The LADIS Battery}

The LADIS neuropsychological battery was constructed with the purpose to evaluate the cognitive performance of a cohort of independent subjects with ARWMC, during a period of 3 years of follow-up. It is a comprehensive but not too long instrument that can be administered on a single visit, making it less unpleasant and intrusive for older patients. This battery was chosen based on the familiarity of the tests and the validity of the instruments to assess the decline of cognitive functions of patients with vascular disease. The LADIS battery explores a whole range of cognitive functions. Along with widely known and validated instruments (MMSE, Stroop and Trail making tests), it included the recently developed VADAS-Cog, which provides detailed information on cognitive global and selective functioning. Although based on the Alzheimer's Disease Assessment Scale (ADAS), theinclusion of time-dependent tasks on VADAS (Symbol digit substitution, Maze tracing, Digit cancellation and Verbal fluency) complemented the evaluation of attention, speed of mental processing and motor control. These cognitive functions, along with executive functioning, are possibly more likely to be affected by white matter changes [29].

The inclusion of memory-specific measures, particularly the 9-word CVLT, during the 2nd and 3rd year of 
Table 4. Influence of demographic variables on neuropsychological performance (t test results)

\begin{tabular}{|c|c|c|c|c|c|c|c|c|c|c|c|c|}
\hline & \multirow[t]{2}{*}{ MMSE } & \multicolumn{6}{|c|}{ Executive functions } & \multicolumn{2}{|c|}{ Attention } & \multicolumn{3}{|c|}{ Speed and motor control } \\
\hline & & $\begin{array}{l}\text { Stroop } \\
3\end{array}$ & $\begin{array}{l}\text { Stroop } \\
3-2\end{array}$ & $\begin{array}{l}\text { Verbal } \\
\text { fluency }\end{array}$ & $\begin{array}{l}\text { TM } \\
\mathrm{B}-\mathrm{A}\end{array}$ & TM B & EXEC & $\mathrm{DC}$ & $\begin{array}{l}\text { Sy } \\
\text { Dig }\end{array}$ & TM A & Maze & speed \\
\hline Age & NS & $-2.63^{\mathrm{a}}$ & $-2.55^{\mathrm{a}}$ & $-2.83^{\mathrm{a}}$ & $-2.86^{b}$ & $-3.40^{\mathrm{a}}$ & $4.68^{\mathrm{a}}$ & $4.94^{\mathrm{a}}$ & $3.72^{\mathrm{a}}$ & $-3.16^{\mathrm{a}}$ & $-2.21^{\mathrm{b}}$ & $4.01^{\mathrm{a}}$ \\
\hline Gender & $-2.31^{\mathrm{b}}$ & NS & NS & NS & NS & NS & NS & NS & NS & NS & $2.54^{\mathrm{b}}$ & NS \\
\hline Education & $-6.66^{\mathrm{a}}$ & $6.01^{\mathrm{a}}$ & $5.14^{\mathrm{a}}$ & $-7.37^{\mathrm{a}}$ & $6.93^{\mathrm{a}}$ & $8.33^{\mathrm{a}}$ & $-10.74^{\mathrm{a}}$ & $-9.80^{\mathrm{a}}$ & $-13.48^{\mathrm{a}}$ & $7.84^{\mathrm{a}}$ & $5.87^{\mathrm{a}}$ & $-8.36^{\mathrm{a}}$ \\
\hline Living conditions & NS & NS & NS & NS & NS & NS & NS & NS & NS & $2.19^{\mathrm{b}}$ & NS & NS \\
\hline Employment status & NS & NS & NS & NS & NS & NS & NS & NS & NS & NS & NS & NS \\
\hline
\end{tabular}

${ }^{\mathrm{a}} \mathrm{p}<0.01 ;{ }^{\mathrm{b}} \mathrm{p}<0.05 . \mathrm{TM}=$ Trail making; EXEC = executive functions compound measure; DC = Digit cancellation; Sy Dig = Symbol digit; Dig Sp = Digit span; Im WR = Immediate word recall; Del WR= Delayed word recall; Word recog. = Word recognition; MEM = memory compound measure; Com = Commands; VC = visuoconstructional; Id = ideational.

Table 5. Influence of demographic variables on neuropsychological performance (linear regression analysis)

\begin{tabular}{|c|c|c|c|c|c|c|c|c|c|c|c|c|}
\hline & \multirow[t]{2}{*}{ MMSE } & \multicolumn{5}{|c|}{ Executive functions } & \multirow[t]{2}{*}{ EXEC } & \multicolumn{2}{|l|}{ Attention } & \multicolumn{3}{|c|}{ Speed and motor control } \\
\hline & & $\begin{array}{l}\text { Stroop } \\
3\end{array}$ & $\begin{array}{l}\text { Stroop } \\
3-2\end{array}$ & $\begin{array}{l}\text { Verbal } \\
\text { fluency }\end{array}$ & $\begin{array}{l}\text { TM } \\
\mathrm{B}-\mathrm{A}\end{array}$ & $\begin{array}{l}\text { TM } \\
\mathrm{B}\end{array}$ & & DC & $\begin{array}{l}\text { Sy } \\
\text { Dig }\end{array}$ & TM A & Maze & speed \\
\hline \multicolumn{13}{|l|}{ Model 1} \\
\hline $\mathrm{R}^{2}$ & $0.12^{\mathrm{a}}$ & $0.07^{\mathrm{a}}$ & $0.05^{\mathrm{a}}$ & $0.12^{\mathrm{a}}$ & $0.12^{\mathrm{a}}$ & $0.18^{\mathrm{a}}$ & $0.22^{\mathrm{a}}$ & $0.18^{\mathrm{a}}$ & $0.27^{\mathrm{a}}$ & $0.14^{\mathrm{a}}$ & $0.10^{\mathrm{a}}$ & $0.16^{\mathrm{a}}$ \\
\hline Age & NS & NS & NS & $-0.14^{\mathrm{a}}$ & $0.15^{\mathrm{a}}$ & $0.18^{\mathrm{a}}$ & $-0.23^{\mathrm{a}}$ & $-0.23^{\mathrm{a}}$ & $-0.18^{\mathrm{a}}$ & $0.13^{\mathrm{a}}$ & NS & $-0.17^{\mathrm{a}}$ \\
\hline Education & $00.33^{\mathrm{a}}$ & $-0.24^{\mathrm{a}}$ & $-0.20^{\mathrm{a}}$ & $0.31^{\mathrm{a}}$ & $-0.31^{\mathrm{a}}$ & $-0.38^{\mathrm{a}}$ & $0.40^{\mathrm{a}}$ & $0.34^{\mathrm{a}}$ & $0.49^{\mathrm{a}}$ & $-0.34^{\mathrm{a}}$ & $0.27^{\mathrm{a}}$ & $0.36^{\mathrm{a}}$ \\
\hline Gender & NS & NS & NS & NS & NS & NS & NS & NS & NS & NS & NS & NS \\
\hline \multicolumn{13}{|l|}{ Model 2} \\
\hline $\mathrm{R}^{2 \text { change }}$ & NS & $0.02^{\mathrm{b}}$ & NS & NS & $0.02^{\mathrm{b}}$ & $0.03^{\mathrm{a}}$ & $0.02^{\mathrm{a}}$ & $0.06^{\mathrm{a}}$ & $0.03^{\mathrm{a}}$ & $0.02^{\mathrm{b}}$ & $0.03^{\mathrm{a}}$ & $0.03^{\mathrm{a}}$ \\
\hline Age & & NS & & & $0.15^{\mathrm{a}}$ & $0.17^{\mathrm{a}}$ & $-0.22^{\mathrm{a}}$ & $-0.22^{\mathrm{a}}$ & $-0.17^{\mathrm{a}}$ & $0.12^{\mathrm{b}}$ & NS & $-0.15^{\mathrm{a}}$ \\
\hline Education & & $-0.22^{\mathrm{a}}$ & & & $-0.29^{\mathrm{a}}$ & $-0.36^{\mathrm{a}}$ & $0.38^{\mathrm{a}}$ & $0.32^{\mathrm{a}}$ & $0.46^{\mathrm{a}}$ & $-0.33^{\mathrm{a}}$ & $-0.26^{\mathrm{a}}$ & $0.34^{\mathrm{a}}$ \\
\hline Gender & & NS & & & NS & NS & NS & NS & NS & NS & NS & NS \\
\hline Any complaint & & NS & & & NS & NS & $-0.10^{\mathrm{b}}$ & $-0.21^{\mathrm{a}}$ & $-0.13^{\mathrm{a}}$ & $0.12^{\mathrm{b}}$ & NS & $-0.12^{\mathrm{b}}$ \\
\hline Stroke & & NS & & & NS & NS & NS & NS & NS & NS & NS & NS \\
\hline Visual deficit & & NS & & & NS & $0.10^{\mathrm{b}}$ & NS & NS & NS & NS & $0.15^{\mathrm{a}}$ & NS \\
\hline \multicolumn{13}{|l|}{ Model 3} \\
\hline $\mathrm{R}^{2 \text { change }}$ & $0.07^{\mathrm{a}}$ & $0.05^{\mathrm{a}}$ & $0.05^{\mathrm{b}}$ & $0.09^{\mathrm{a}}$ & $0.10^{\mathrm{a}}$ & $0.13^{\mathrm{a}}$ & $0.10^{\mathrm{a}}$ & $0.07^{\mathrm{a}}$ & $0.08^{\mathrm{a}}$ & $0.10^{\mathrm{a}}$ & $0.11^{\mathrm{a}}$ & $0.10^{\mathrm{a}}$ \\
\hline Age & NS & NS & NS & $-0.16^{\mathrm{a}}$ & $0.16^{\mathrm{a}}$ & $0.18^{\mathrm{a}}$ & $-0.22^{\mathrm{a}}$ & $-0.22^{\mathrm{a}}$ & $-0.18^{\mathrm{a}}$ & $0.12^{\mathrm{a}}$ & $0.12^{\mathrm{b}}$ & $-0.17^{\mathrm{a}}$ \\
\hline Education & $0.37^{\mathrm{a}}$ & $-0.20^{\mathrm{a}}$ & $-0.17^{\mathrm{a}}$ & $0.29^{\mathrm{a}}$ & $-0.30^{\mathrm{a}}$ & $-0.33^{\mathrm{a}}$ & $0.37^{\mathrm{a}}$ & $0.26^{\mathrm{a}}$ & $0.43^{\mathrm{a}}$ & $-0.25^{\mathrm{a}}$ & $-0.21^{\mathrm{a}}$ & $0.27^{\mathrm{a}}$ \\
\hline Gender & NS & NS & NS & NS & NS & NS & NS & NS & NS & NS & NS & NS \\
\hline Any complaint & NS & NS & NS & NS & $0.15^{\mathrm{b}}$ & $0.14^{\mathrm{b}}$ & $-0.12^{\mathrm{b}}$ & $-0.12^{\mathrm{b}}$ & NS & NS & NS & NS \\
\hline Stroke & NS & NS & NS & NS & NS & NS & NS & NS & NS & NS & NS & NS \\
\hline Visual deficit & NS & NS & NS & NS & $0.10^{\mathrm{b}}$ & $0.11^{\mathrm{b}}$ & NS & NS & NS & NS & NS & NS \\
\hline \multirow[t]{7}{*}{ Center } & $\mathrm{HU}$ & $\mathrm{CO}-0.20^{\mathrm{b}}$ & $\mathrm{CO}-0.14^{\mathrm{a}}$ & CO $0.20^{\mathrm{a}}$ & $\mathrm{CO}-0.18^{\mathrm{a}}$ & $\mathrm{CO}-0.22^{\mathrm{b}}$ & $\mathrm{AM}-0.14^{\mathrm{b}}$ & $\mathrm{CO} 0.13^{\mathrm{b}}$ & $\mathrm{CO} 0.19^{\mathrm{a}}$ & $\mathrm{CO}-0.21^{\mathrm{a}}$ & all & all \\
\hline & $-0.18^{\mathrm{a}}$ & $\mathrm{GO}-0.17^{\mathrm{b}}$ & $\mathrm{GO}-0.15^{\mathrm{b}}$ & HE $0.13^{b}$ & $\mathrm{HU}-0.13^{\mathrm{b}}$ & FL $0.13^{\mathrm{b}}$ & $\mathrm{CO} 0.14^{\mathrm{b}}$ & $\mathrm{FL}-0.12^{\mathrm{b}}$ & HU $0.16^{\mathrm{a}}$ & $\mathrm{GO}-0.14^{\mathrm{b}}$ & centers & except \\
\hline & & & & & & $\mathrm{GO}-0.16^{\mathrm{b}}$ & $\mathrm{FL}-0.18^{\mathrm{b}}$ & GO $0.13^{b}$ & $\mathrm{NC} 0.15^{\mathrm{b}}$ & GR $-0.14^{\mathrm{b}}$ & & $\mathrm{PA}$ and \\
\hline & & & & & & $\mathrm{HU}-0.20^{\mathrm{a}}$ & & $\mathrm{NC} 0.21^{\mathrm{a}}$ & & $\mathrm{HE}-0.13^{\mathrm{b}}$ & & FL \\
\hline & & & & & & & & & & $\mathrm{HU}-0.22^{\mathrm{a}}$ & & \\
\hline & & & & & & & & & & $\mathrm{MA}-0.15^{\mathrm{b}}$ & & \\
\hline & & & & & & & & & & $\mathrm{NC}-0.21^{\mathrm{a}}$ & & \\
\hline
\end{tabular}

Values are standardized $\beta .{ }^{\mathrm{a}} \mathrm{p}<0.001 ;{ }^{\mathrm{b}} \mathrm{p}<0.01 ; \mathrm{NS}=\mathrm{p}>0.05$. TM = Trail making; EXEC = executive functions compound measure; DC = Digit cancellation; Sy Dig = Symbol digit; Dig Sp = Digit span; Im WR = Immediate word recall; Del WR = Delayed word recall; Word recog. = Word recognition; $\mathrm{MEM}=$ memory compound measure; $\mathrm{Com}=\mathrm{Commands}$, VC = visuoconstructional; $\mathrm{Id}=\mathrm{ideational} ; \mathrm{AM}=\mathrm{Amsterdam}$; $\mathrm{CO}=\mathrm{Copenhagen} ; \mathrm{FL}=$ Florence; $\mathrm{GO}=$ Goteborg; GR = Graz; HE = Helsinki; HU = Huddinge; LS = Lisbon; MA = Mannheim; NC = Newcastle; PA = Paris. 


\begin{tabular}{|c|c|c|c|c|c|c|c|c|c|}
\hline \multicolumn{5}{|c|}{ Memory } & \multicolumn{2}{|c|}{ Language } & \multicolumn{2}{|l|}{ Praxis } & ADAS-Total \\
\hline NS & NS & NS & NS & NS & NS & NS & $3.18^{\mathrm{a}}$ & NS & NS \\
\hline$-9.41^{\mathrm{a}}$ & NS & $5.83^{\mathrm{a}}$ & NS & $-4.99^{\mathrm{a}}$ & NS & $6.7^{\mathrm{a}}$ & $5.39^{\mathrm{a}}$ & $2.97^{\mathrm{a}}$ & $5.69^{\mathrm{a}}$ \\
\hline NS & NS & NS & NS & NS & NS & NS & NS & NS & NS \\
\hline NS & NS & NS & NS & NS & $-3.28^{\mathrm{a}}$ & NS & NS & NS & NS \\
\hline
\end{tabular}

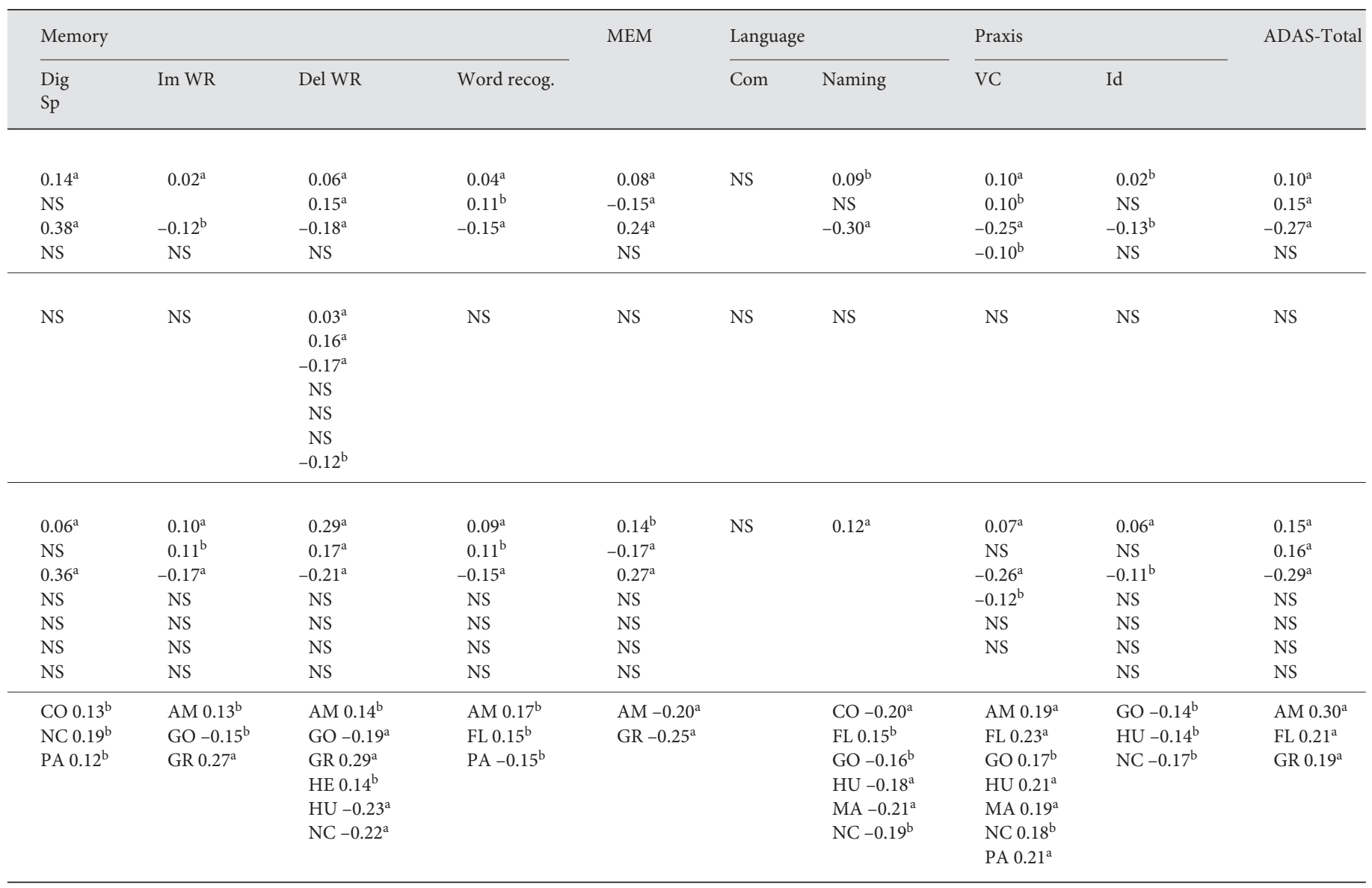


follow-up, was adopted as a way to improve the evaluation of memory decline minimizing the learning effect that might occur if the memory test or the VADAS word recall subtest were administered four times instead of two.

The use of the same version and guidelines for administration of the tests in all the centers reduced the heterogeneity of the cognitive evaluation and allowed the appropriate evaluation of the whole sample of the LADIS cohort.

Nevertheless, the neuropsychological battery adopted in the LADIS study has some limitations: (1) when trying to reduce the time to administer the cognitive battery by using one trial instead of three, as described in the original version of the VADAS subtest Word recall, we did not include any measure of learning memory on the baseline assessment and compromised the possibility of comparing the results of the LADIS sample with other studies that use the same instrument. However, this limitation was minimized by the inclusion of the 9-word CVLT during the second and third follow-up visits; (2) the test versions adopted were not validated in each center/country and there is no control group to compare the results of the LADIS sample. The absence of a control group is due to the fact that it would be necessary to perform MRI on normal volunteers and that would increase enormously the costs of the study; (3) using a handbook with all the administration norms for each test, we tried to reduce the differences concerning the training of the examiners that could lead to differences on the results.

\section{Neuropsychological Data Analysis}

Differences among centers were observed for almost all the tests except Naming and Ideational praxis. However, the differences were randomly distributed and no consistent pattern was found. Cultural and educational variables might explain some of the differences between centers. Despite that, when Florence and Lisbon (which had the lowest mean education level) were excluded from the analysis, differences among centers remained.

We found that, when compared with younger subjects, older subjects performed significantly worse on Trail making, Symbol digit, Digit cancellation tests and on executive functions and memory compound measures. Age remained an independent variable influencing the performance in memory and executive function domains even when controlling for ARWMC severity. The effect of age on neuropsychological performance of healthy subjects with ARWMC was also reported by Ylikoski et al. [6], who found that cognitive performance decreased on memory tests, constructional abilities, language, timed tests and speed of mental processing. Our results are similar to those found in that work.

Education was the most consistent factor influencing the performance in all the neuropsychological tests and domains. The association between education and cognitive performance remained significant in the presence of ARWMC. Memory performance seems to be independent of the effect of education. This could be explained by the fact that in the baseline assessment of our study, memory was mainly evaluated verbally (Word recall, Delayed recall, Word recognition, Digit span), reducing the influence of education on pencil/paper tests. Education seems to play a more important role on complex tasks such as executive functions. One study evaluating mainly speed and executive functions [30] reported the influence of education on the cognitive performance of a sample of elderly subjects with ARWMC. Dufouil et al. [30] found no relationship between WMC severity and cognitive performance in participants with a high level of education, reinforcing the hypothesis of the cognitive reserve [31]. Independent of the way it influences cognition, education should be considered as a covariate variable in analyzing the effect of ARWMC on neuropsychological performance.

In the LADIS sample, women performed worse on MMSE, Constructional praxis and Mazes. Female gender has been associated with difficulties performing visuoconstructional tasks and spatial orientation, which could explain the difficulties in performing both Constructional praxis and Maze task. Although some studies [9, 32] reported a prevalence of earlier and more severe ARWMC in women, in our sample the prevalence and severity of ARWMC was similar for both sexes. In our study, women tended to have less years of education, which might explain the difference on the MMSE. Ott et al. [33] in a large populational study, reported a stronger association between low education and dementia in women than in men. However, in a recent study, Ruitenberg et al. [34] found that this association was mainly significant among people over 90 years old and that the incidence of dementia was similar for both sexes before this high age.

In our study, the analysis of the baseline neuropsychological data showed a significant influence of demographic variables on cognitive performance. Neuropsychological performance in patients with ARWMC was influenced by age and education. Higher educational level was consistently associated with better performances on cognitive tasks, while older age was associated with 
difficulties in memory and executive functions. The analysis performed on neuropsychological data in the LADIS study will, thus, have to use age and education as modifiers, and therefore as covariables.

\section{Acknowledgements}

The LADIS study is supported by the European Union within the 5th European Framework Program 'Quality of Life and Management of Living Resources' (1998-2002), contract QLRT-200000446 as a concerted action.

\section{Appendix 1}

\section{List of Participating Centers and Personnel}

Helsinki, Finland (Memory Research Unit, Department of Clinical Neurosciences, Helsinki University): Timo Erkinjuntti, MD, PhD, Tarja Pohjasvaara, MD, PhD, Pia Pihanen, MD, Raija Ylikoski, PhD, Hanna Jokinen, LPsych, Meija-Marjut Somerkoski, MPsych; Graz, Austria (Department of Neurology and MRI Institute, Karl Franzens University): Franz Fazekas, MD, Reinhold Schmidt, MD, Stefan Ropele, PhD, Brigitte Rous, MD, Katja Petrovic, MagPsychol, Ulrike Garmehi; Lisboa, Portugal (Serviço de Neurologia, Centro de Estudos Egas Moniz, Hospital de Santa Maria): José M. Ferro, MD, PhD, Ana Verdelho, MD, Sofia Madureira, PsyD; Amsterdam, The Netherlands (Department of Neurology, VU Medical Center): Philip Scheltens, MD, PhD, Ilse van Straaten, MD, Frederik Barkhof, MD, PhD; Göteborg, Sweden
(Institute of Clinical Neuroscience, Göteborg University): Anders Wallin, MD, PhD, Michael Jonsson, MD, Karin Lind, MD, Arto Nordlund, PsyD, Sindre Rolstad, PsyD, Kerstin Gustavsson, RN; Huddinge, Sweden (Karolinska Institute, Department of Clinical Neuroscience and Family Medicine, Huddinge University Hospital): Lars-Olof Wahlund, $\mathrm{MD}, \mathrm{PhD}$, Militta Crisby, MD, $\mathrm{PhD}$, Anna Pettersson, physiotherapist, Kaarina Amberla, PsyD; Paris, France (Department of Neurology, Hopital Lariboisière): Hugues Chabriat, MD, PhD, Ludovic Benoit, MD, Karen Hernandez, Solene Pointeau, Annie Kurtz, Daniel Reizine, MD; Mannheim, Germany (Department of Neurology, University of Heidelberg, Klinikum Mannheim): Michael Hennerici, MD, Christian Blahak, MD, Hansjörg Baezner, MD, Martin Wiarda, PsyD, Susanne Seip, RN; Copenhagen, Denmark (Memory Disorders Research Unit, Department of Neurology, Copenhagen University Hospital): Gunhild Waldemar, MD, DMSc, Egill Rostrup, MD, MSc; Newcastle-upon-Tyne, UK (Institute for Ageing and Health, University of Newcastle): John O'Brien, DM, Sanjeet Pakrasi, MRCPsych, Thais Minnet, PhD, Michael Firbank, PhD, Jenny Dean, PhD, Pascale Harrison, BSc, Philip English, DCR. The Coordinating Center is in Florence, Italy (Department of Neurological and Psychiatric Sciences, University of Florence): Domenico Inzitari, MD (study coordinator); Leonardo Pantoni, MD, PhD, Anna Maria Basile, MD, Michela Simoni, MD, Giovanni Pracucci, MD, Monica Martini, MD, Luciano Bartolini, PhD, Emilia Salvadori, $\mathrm{PhD}$, Marco Moretti, MD, Mario Mascalchi, MD, PhD, Giovanna Carlucci, MD, PhD, Anna Poggesi, MD, Eliana Magnani, MD. The LADIS Steering Committee is formed by Domenico Inzitari, MD (study coordinator), Timo Erkinjuntti, MD, PhD, Philip Scheltens, MD, PhD, Marieke Visser, MD, PhD, and Kjell Asplund, $\mathrm{MD}, \mathrm{PhD}$.

\section{References}

1 Ferro J, Madureira S: Age-related white matter changes and cognitive impairment. J Neurol Scie 2002;203-204:221-225.

-2 Pantoni L, Leys D, Fazekas F, Longstreth WT, Inzitari D, Wallin A, Filippi M, Scheltens P, Erkinjuntti T, Hachinski VC: Role of white matter lesions in cognitive impairment of vascular origin. Alzheimer Dis Assoc Dis 1999;13:S49-S54.

$\checkmark 3$ Matsubayashi K, Shimada K, Kawamoto A, Ozawa T: Incidental brain lesions on magnetic resonance imaging and neurobehavioral functions in the apparently healthy elderly. Stroke 1992;23:175-180.

4 Skoog I BS, Johansson B, Palmertz B, Andreasson LA: The influence of white matter lesions on neuropsychological functioning in demented and non-demented 85-years-olds. Acta Neurol Scand 1996;93:142-148.

$\checkmark 5$ Longstreth WT, Manolio TA, Arnold A: Clinical correlates of white matter findings on cranial magnetic resonance imaging of 3301 elderly people: the Cardiovascular Health Study. Stroke 1996;27:1274-1282.
6 Ylikoski R, Ylikoski A, Erkinjuntti T, Sulkava $\mathrm{R}$, Raininko $\mathrm{R}$, Tilvis R: White matter changes in healthy elderly persons correlate with attention and speed of mental process ing. Arch Neurol 1993;50:818-824.

7 Schmidt R, Fazekas F, Offenbacher H: Neuropsychological correlates of MRI white matter hyperintensities: a study of 150 normal volunteers. Neurology 1993;43:24902494.

$\checkmark 8$ De Carli C, Murphy D, Tranh M, Grady C, Haxby J, Gillette J, Gonzalez-Aviles A, Rapoport S: The effect of white matter hyperintensity volume on brain structure, cognitive performance and cerebral metabolism of glucose in 51 healthy adults. Neurology 1995 ; 45:2077-2084.

9 Breteler MM, Swieten JCV, Bots ML: Cerebral white matter lesions, vascular risk factors and cognitive function in a populationbased study: the Rotterdam Study. Neurology 1994;44:1246-1253.

10 Boone KB, Miller BL, Lesser IM: Neuropsychological correlates of white matter lesions in the elderly subjects: a threshold effect. Arch Neurol 1992;49:549-554.
11 Rao SM, Mittenberg W, Bernardin L: Neuropsychological test findings in subject with leukoaraiosis. Arch Neurol 1989;46:40-44.

12 Fein G, van Dyke C, Davenport L, Turetsky B, Brant-Zawadzki M, Zatz L: Preservation of normal cognitive function in elderly subjects with extensive white-matter lesions of long duration. Arch Gen Psychiatry 1990;47: 220-223.

-13 Pantoni L, Basile A, Pracucci G, Asplund K, Bogousslavsky J, Chabriat H, Erkinjuntti T, Fazekas F, Ferro J, Hennerici M, O’Brien J, Scheltens P, Visser M, Wahlund L, Waldemar G, Wallin A, Inzitari D: Impact of agerelated cerebral white matter changes on the transition to disability - The LADIS Study: rationale, design and methodology. Neuroepidemiology 2004;24:51-62.

14 Folstein M, Folstein S, McHugh PJ: MiniMental State: a practical method for grading the cognitive state of patients for clinicians. J Psychiatr Res 1975;12:189-198.

15 Stroop JR: Studies of interference in serial verbal reactions. J Exp Psychol 1935;18:643662 
16 McLeod CM: Half a century of research on the Stroop effect: an integrative review. Psychol Bull 1991;109:163-203.

-17 Grant DA, Berg EA: A behavioural analysis of degree of impairment and case of shifting to new responses in a Weigl-type card sorting problem. J Exp Psychol 1948;39:404411.

18 Reitan R: Validity of the Trail Making test as an indicator of organic brain damage. Percept Mot Skills 1958;8:271-276.

19 Ferris S: General measures of cognition. Int Psychogeriatr 2003;15:215-217.

-20 Rosen W, Mohs R, Davis K: A new rating scale for Alzheimer's disease. Am J Psychiatry 1984;141:1356-1364.

21 Lezak MD: Neuropsychological Assessment, ed 3. New York, Oxford University Press, 1995.

22 Spreen O, Strauss E: A compendium of neuropsychological tests: administration, norms and commentary, ed 2. New York, Oxford University Press, 1998.

-23 Inzitari D, Rossi R, Lamassa M, Mugnai S, Carlucci G, Bianchi C, Amaducci L: Validity of different linguistic versions of the Alzheimer's Disease Assessment Scale in an international multicentre Alzheimer's disease trial. Dement Geriatr Cogn Disord 1999;10: 269-277.
24 Libon D, Mattson R, Glosser G, Kaplan E, Malamut B, Sands LP, Swenson R, Cloud B: A nine-word version of the California Verbal Learning Test. Clin Neuropsychol 1996;10: 237-244.

25 Morris JC, Heyman A, Mohs RC, Cohen L: The Consortium to Establish a Registry for Alzheimer's Disease (CERAD). I. Clinical and neuropsychological assessment of Alzheimer's disease. Neurology 1989;39:119_ 1165.

26 Brandt J, Spencer M, Folstein M: The telephone interview for cognitive status. Neuropsychiatry Neuropsychol Behav Neurol 1988;1:111-117.

27 Gropu PC: Effects of blood pressure lowering with perindopril and indapamide therapy on dementia and cognitive decline in patients with cerebrovascular disease. Arch Intern Med 2003;163:1069-1075.

28 Fazekas F, Chawluk J, Alavi A, Hurting H, Zimmerman R: MR Signal abnormalities at 1.5T in Alzheimer's dementia and norma aging. Am J Neuroradiol 1987;8:421-426.
29 Mohs R, Knopman D, Peterson R: Development of cognitive instruments for use in clinical trials of antidementia drugs: additions to the Alzheimer's disease assessment Scale (ADAS) that broaden its scope. Alzheimer Dis Assoc Disord 1997;11:S13-S21.

30 Dufouil C, Alpérovitch A, Tzourio C: Influence of education on the relationship between white matter lesions and cognition. Neurology 2003;60:831-836.

-31 Stern Y, Gurland B, Alexandre G, Prohovnic I, MAyeux R: Inverse relationship between education and parietotemporal perfusion deficit in Alzheimer's disease. Ann Neurol 1992;32:371-375.

32 de Leeuw FE, Groot J, Achten E, Oudkerk M, Ramos L, Heijboer R, Hofman A, Jolles J, van Gijn J, Breteler M: Prevalence of cerebral white matter lesions in elderly people: a population based magnetic resonance imaging study. The Rotterdam Scan Study. J Neurol Neurosurg Psychiatry 2001;70:9-14.

33 Ott A, van Rossum C, van Harskamp F, van de Mheen H, Hofman A, Breteler MM: Education and the incidence of dementia in a large population-based study: the Rotterdam Study. Neurology 1999;52:663-666.

-34 Ruitenberg A, Ott A, van Swieten J, Hofman A, Breteler M: Incidence of dementia: does gender make a difference? Neurobiol Aging 2001;22:575-580. 